Pacific Journal of Mathematics

ON STABLE PARALLELIZABILITY OF FLAG MANIFOLDS 


\title{
ON STABLE PARALLELIZABILITY OF FLAG MANIFOLDS
}

\author{
P. SANKARAN AND P. ZVENGROWSKI
}

\begin{abstract}
It was shown by Trew and Zvengrowski that the only Grassmann manifolds that are stably parallelizable as real manifolds are $G_{1}\left(F^{2}\right)$, $G_{1}\left(\mathbf{R}^{4}\right) \cong G_{3}\left(\mathbf{R}^{4}\right)$, and $G_{1}\left(\mathbf{R}^{8}\right) \cong G_{7}\left(\mathbf{R}^{8}\right)$ where $F=\mathbf{R}, \mathbf{C}$, or $\mathbf{H}$, the case $F=\mathbf{R}$ having also been previously treated by several authors. In this paper we solve the more general question of stable parallelizability of $F$-flag manifolds, $F=\mathbf{R}, \mathrm{C}$, or $\mathrm{H}$. Only elementary vector bundle concepts are used. The real case has also been recently solved by Korbaš using Stiefel-Whitney classes.
\end{abstract}

THEOREM 1. Let $s \geq 3, \mu=\left(n_{1}, \ldots, n_{s}\right)$. Then

(i) $F G(\mu)$ is stably parallelizable if $n_{1}=\cdots=n_{s}=1$, and parallelizable only when $F=\mathbf{R}$.

(ii) If $n_{i}>1$ for some $i$ then $F G(\mu)$ is not stably parallelizable.

Note that the case $s=2$ is just that of Grassmann manifolds, which is already known. In $\S 1$ the proof of Theorem 1 is given. An explicit trivialization of the tangent bundle of $\operatorname{R} G(1, \ldots, 1)$ is constructed in $\$ 2$. We remark that similar questions can be asked of the "partially oriented" flag manifolds, that is manifolds of flags $\left(\sigma_{1}, \ldots, \sigma_{s}\right), \operatorname{dim} \sigma_{i}=n_{i}$, in which some of the $\sigma_{i}$ are oriented (cf. [5]). Results on these questions will be given in a later paper.

\section{Proof of Theorem 1.}

Proof of (i). Let $\mu=\left(n_{1}, \ldots, n_{s}\right)$ with $n_{i}=1$. The stable parallelizability of $F G(\mu)$ has been noted by Lam in [4]. The parallelizability of $\mathbf{R} G(\mu) \cong O(n) /(O(1) \times \cdots \times O(1))$ is explicitly shown in $\$ 2$ below. However, it can also be deduced from the theorem that the quotient of a Lie group by a finite subgroup is parallelizable (cf. [3] or [2], p. 502). To prove that $F G(\mu)$ is not parallelizable for $G=\mathbf{C}$ or $\mathbf{H}$ we show that the Euler characteristic in these cases is non-zero. Note that $\pi_{n}: \quad F G(\mu) \rightarrow F P^{n-1} \cong F G(n-1,1)$, the projection map that sends $\left(A_{1}, \ldots, A_{n}\right)$ to $A_{n} \in F P^{n-1}$, is a bundle map with fibre $F G\left(\mu_{s-1}\right)\left(\mu_{s-1}\right.$ $\left.=\left(n_{1}, \ldots, n_{s-1}\right)\right)$. 
This bundle is orientable for $F=\mathbf{C}$ or $\mathbf{H}$. Further, $\chi\left(F P^{m}\right)>0$ for $F=\mathbf{C}, \mathbf{H}$ and $m \geq 1$. Using induction and the multiplicative property of Euler characteristic we see that $\chi(F G(\mu))>0$ for $F=\mathbf{C}$ or $\mathbf{H}$.

Proof of (ii). Since $F G\left(n_{1}, \ldots, n_{s}\right) \cong F G\left(n_{l_{1}}, \ldots, n_{i_{s}}\right)$ where $\left\{i_{1}, \ldots, i_{s}\right\}=\{1, \ldots, s\}$ we assume, without loss of generality, that $n_{1} \geq \cdots \geq n_{s}$. Now let $n_{1}>1$. By [4] one has the following description of the tangent bundle $\tau^{F}(\mu)$ of $F G(\mu)$ :

$$
\tau^{F}(\mu) \approx_{Z(F)} \bigoplus_{1 \leq i<j \leq s} \bar{\xi}_{i}^{F}(\mu) \otimes_{F} \xi_{j}^{F}(\mu)
$$

where $\xi_{i}(\mu)$ denotes the canonical $F$-vector bundle of rank $n_{i}$ over $F G(\mu)$ and $\bar{\xi}_{i}^{F}(\mu)$ its conjugate bundle for $1 \leq i \leq s$. Note that

$$
\xi_{1}^{F}(\mu) \oplus \cdots \oplus \xi_{s}^{F}(\mu) \approx \varepsilon_{n}^{F}
$$

where $\varepsilon_{n}^{F}$ is the trivial $F$-vector bundle of rank $n$.

Now consider the inclusion $i: F G\left(\mu_{s-1}\right) \rightarrow F G(\mu)$ which is induced by the identification $F^{|\mu|} \cong F^{\left|\mu_{s-1}\right|} \oplus F^{n_{s}}$. Clearly

$$
\begin{aligned}
& i^{*}\left(\xi_{i}^{F}(\mu)\right) \approx \xi_{i}^{F}\left(\mu_{s-1}\right) \quad \text { for } 1 \leq i \leq s-1 \text { and } \\
& i^{*}\left(\xi_{s}^{F}(\mu)\right) \approx \varepsilon_{n_{s}}^{F} .
\end{aligned}
$$

Therefore, denoting stable equivalence of $Z(F)$-bundles by $\sim$,

$$
\begin{aligned}
i^{*}\left(\tau^{F}(\mu)\right) & \approx i *\left(\bigoplus_{1 \leq i<j \leq s} \bar{\xi}_{i}^{F}(\mu) \otimes \xi_{j}^{F}(\mu)\right) \\
& \approx \bigoplus_{1 \leq i<j \leq s-1} \bar{\xi}_{i}^{F}\left(\mu_{s-1}\right) \otimes \xi_{j}^{F}\left(\mu_{s-1}\right) \bigoplus_{1 \leq i \leq s-1} \bar{\xi}_{i}^{F}\left(\mu_{s-1}\right) \otimes \varepsilon_{n_{s}}^{F} \\
& \sim \tau^{F}\left(\mu_{s-1}\right) \text { since } \bigoplus_{1 \leq i \leq s-1} \bar{\xi}_{i}^{F}\left(\mu_{s-1}\right) \approx \bar{\varepsilon}_{\left|\mu_{s-1}\right|}^{F} .
\end{aligned}
$$

Let $j$ be the composition of the inclusions

$$
F G\left(\mu_{2}\right) \stackrel{i}{\rightarrow} \cdots \stackrel{i}{\rightarrow} F G(\mu) .
$$

By applying $i^{*}$ successively, we obtain

$$
j^{*}\left(\tau^{F}(\mu)\right) \sim \tau^{F}\left(\mu_{2}\right)
$$

Now the conclusion of Theorem 1(ii) follows from the negative results on the stable parallelizability of Grassmann manifolds except when $F=\mathbf{R}$, $n_{2}=1$ and $n_{1}=3$ or 7 (see [6]). 
We now consider the double covering

$$
P V_{\mathbf{R}}(n, 2) \stackrel{p}{\rightarrow} \mathbf{R} G(n-2,1,1)
$$

where $P V_{\mathbf{R}}(n, k)$ is the projective Stiefel manifold obtained by identifying $a$ with $-a$ for $a \in V_{n, k}, \quad n \geq k \geq 1$. If $[\underline{a}] \in P V_{\mathbf{R}}(n, 2)$, where $\underline{a}=\left(a_{1}, a_{2}\right) \in V_{n, 2}$,

$$
p([\underline{a}])=\left(\left\{a_{1}, a_{2}\right\}^{\perp}, \mathbf{R} a_{1}, \mathbf{R} a_{2}\right) \in \mathbf{R} G(n-2,1,1) .
$$

As for any covering map, we have

$$
p^{*}\left(\tau^{\mathbf{R}}(n-2,1,1)\right) \approx \tau\left(P V_{\mathbf{R}}(n, 2)\right) .
$$

From the results of Antoniano [1] we know that $P V_{\mathbf{R}}(5,2)$ and $P V_{\mathbf{R}}(9,2)$ are not stably parallelizable. Consequently $\tau^{\mathbf{R}}(3,1,1)$ and $\tau^{\mathbf{R}}(7,1,1)$ are not stably parallelizable, completing the proof in all cases.

REMARK. The top Chern class of $\mathbf{C} G(1, \ldots, 1)$ is its Euler class. Since the Euler characteristic of $\mathbf{C} G(1, \ldots, 1)$ is non-zero it follows that the top Chern class of $\tau^{\mathbf{C}}(1, \ldots, 1)$ is non-zero. Hence $\mathbf{C} G(1, \ldots, 1)$ is not stably parallelizable as a complex manifold.

2. Parallelizability of $\mathbf{R} G(1, \ldots, 1)$. We conclude this paper by constructing an explicit trivialization for $\tau^{\mathbf{R}}(1, \ldots, 1)$.

For each pair of integers $k$ and $l, 1 \leq k<l \leq n$, we will construct a tangent vector field $\varphi_{k l}$ and show that these $\left(\begin{array}{l}n \\ 2\end{array}\right)$ vector fields are everywhere linearly independent. Since $\operatorname{dim} \operatorname{R} G(1, \ldots, 1)=\left(\begin{array}{c}n \\ 2\end{array}\right)$, the space is therefore parallelizable.

Let $\underline{a}=\left(\left[a_{1}\right], \ldots,\left[a_{n}\right]\right) \in \mathbf{R} G(1, \ldots, 1)$ where $\left\{a_{1}, \ldots, a_{n}\right\}$ is an orthonormal basis for $\mathbf{R}^{n}$, and $\left[a_{i}\right]=\left[-a_{i}\right]=\left\{a_{l},-a_{i}\right\}$. Define $\varphi_{k l}$ as follows: Writing $a_{i}=\left(a_{i 1}, \ldots, a_{i n}\right) \in \mathbf{R}^{n}$ for $1 \leq i \leq n$,

$$
\varphi_{k l}(\underline{a})=\sum_{1 \leq i<j \leq n}\left(a_{i k} a_{j l}-a_{i l} a_{j k}\right) a_{i} \otimes a_{j}, \quad 1 \leq k<l \leq n .
$$

It is clear that $\varphi_{k l}: \mathbf{R} G(1, \ldots, 1) \rightarrow T^{\mathbf{R}}(1, \ldots, 1)$, the total space of the tangent bundle $\tau^{\mathbf{R}}(1, \ldots, 1) \approx \oplus_{1 \leq i<j \leq n} \xi_{l} \otimes \xi_{j}$ is well-defined and continuous.

Now consider the homomorphism $f: \bigoplus_{1 \leq i<j \leq n} A_{i} \otimes A_{J} \rightarrow \Lambda^{2}\left(\mathbf{R}^{n}\right)$ defined by

$$
f\left(a_{i} \otimes a_{j}\right)=a_{i} \wedge a_{j}
$$

where $A_{i}=\mathbf{R} a_{i}$. Since $\left\{a_{1}, \ldots, a_{n}\right\}$ is an orthonormal basis for $\mathbf{R}^{n}$, $\left\{a_{i} \wedge a_{j} \mid 1 \leq i<j \leq n\right\}$ is an orthonormal basis for $\Lambda^{2}\left(\mathbf{R}^{n}\right)$. Therefore $f$ 
preserves inner products and is an isomorphism. Now

$$
f \varphi_{k l}(\underline{a})=\sum_{1 \leq i<j \leq n}\left(a_{i k} a_{j l}-a_{j k} a_{i l}\right) a_{i} \wedge a_{j}=u_{k} \wedge u_{l}
$$

where $u_{k}=\sum a_{i k} a_{i}=\sum a_{i k} a_{i m} e_{m}=\sum \delta_{k m} e_{m}=e_{k},\left\{e_{1}, \ldots, e_{n}\right\}$ being the standard orthonormal basis of $\mathbf{R}^{n}$. Therefore

$$
\left\{f \varphi_{k l}(\underline{a}) \mid 1 \leq k<l \leq n\right\}=\left\{e_{k} \wedge e_{l} \mid 1 \leq k<l \leq n\right\}
$$

is an orthonormal basis for $\Lambda^{2}\left(\mathbf{R}^{n}\right)$. Consequently $\left\{\varphi_{k l}(\underline{a}) \mid 1 \leq k<l \leq n\right\}$ is an orthonormal basis for the tangent space at $\underline{a}$ to $\mathbf{R} G(1, \ldots, 1)$. Since $\underline{a} \in \mathbf{R} G(1, \ldots, 1)$ was arbitrary, it follows that $\left\{\varphi_{k l} \mid 1 \leq k<l \leq n\right\}$ is everywhere linearly independent.

\section{REFERENCES}

[1] E. Antoniano, Sobre las variedades de Stiefel proyectivas, Tesis CIEA del IPN, México, D. F. (1976).

[2] A. Borel and F. Hirzebruch, Characteristic classes and homogeneous spaces, III, Amer. J. Math., 82 (1960), 491-504.

[3] J. Korbaš, Vector fields on real flag manifolds, to appear.

[4] K. Y. Lam, A formula for the tangent bundle of flag manifolds and related manifolds, Trans. Amer. Math. Soc., 213 (1975), 305-314.

[5] I. D. Miatello and R. J. Miatello, On stable parallelizability of $\tilde{G}_{k, n}$ and related manifolds, Math. Ann., 259 (1982), 343-350.

[6] S. Trew and P. Zvengrowski, Non-parallelizability of Grassmann manifolds, Canad. Math. Bull., 27 (1), (1984), 127-128.

Received January 24, 1985.

The University of Calgary

Calgary, Alberta

CANADA T2N $1 \mathrm{~N} 4$ 


\section{PACIFIC JOURNAL OF MATHEMATICS EDITORS}

\author{
V. S. VARAdarajan (Managing Editor) \\ University of California \\ Los Angeles, CA 90024 \\ Hebert Clemens \\ University of Utah \\ Salt Lake City, UT 84112 \\ Charles R. DePrima \\ California Institute of Technology \\ Pasadena, CA 91125
}

R. FINN

Stanford University

Stanford, CA 94305

HeRManN FLASChKa

University of Arizona

Tucson, AZ 85721

RAMESH A. GANGOlli

University of Washington

Seattle, WA 98195

ROBION KIRBY

University of California

Berkeley, CA 94720

\author{
C. C. MOORE \\ University of California \\ Berkeley, CA 94720 \\ H. SAMELSON \\ Stanford University \\ Stanford, CA 94305 \\ HAROLD STARK \\ University of California, San Diego \\ La Jolla, CA 92093
}

\section{ASSOCIATE EDITORS}

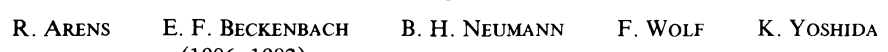

(1906-1982)

\section{SUPPORTING INSTITUTIONS}

\begin{abstract}
UNIVERSITY OF ARIZONA
UNIVERSITY OF BRITISH COLUMBIA

CALIFORNIA INSTITUTE OF TECHNOLOGY

UNIVERSITY OF CALIFORNIA

MONTANA STATE UNIVERSITY

UNIVERSITY OF NEVADA, RENO

NEW MEXICO STATE UNIVERSITY

OREGON STATE UNIVERSITY
\end{abstract}

\author{
UNIVERSITY OF OREGON \\ UNIVERSITY OF SOUTHERN CALIFORNIA \\ STANFORD UNIVERSITY \\ UNIVERSITY OF HAWAII \\ UNIVERSITY OF TOKYO \\ UNIVERSITY OF UTAH \\ WASHINGTON STATE UNIVERSITY \\ UNIVERSITY OF WASHINGTON
}

The Supporting Institutions listed above contribute to the cost of publication of this Journal, but they are not owners or publishers and have no responsibility for its content or policies.

Mathematical papers intended for publication in the Pacific Journal of Mathematics should be in typed form or offset-reproduced (not dittoed), double spaced with large margins. Please do not use built up fractions in the text of the manuscript. However, you may use them in the displayed equations. Underline Greek letters in red, German in green, and script in blue. The first paragraph must be capable of being used separately as a synopsis of the entire paper. In particular it should contain no bibliographic references. Please propose a heading for the odd numbered pages of less than 35 characters. Manuscripts, in triplicate, may be sent to any one of the editors. Please classify according to the scheme of Math. Reviews, Index to Vol. 39. Supply name and address of author to whom proofs should be sent. All other communications should be addressed to the managing editor, or Elaine Barth, University of California, Los Angeles, California 90024.

There are page-charges associated with articles appearing in the Pacific Journal of Mathematics. These charges are expected to be paid by the author's University, Government Agency or Company. If the author or authors do not have access to such Institutional support these charges are waived. Single authors will receive 50 free reprints; joint authors will receive a total of 100 free reprints. Additional copies may be obtained at cost in multiples of 50 .

The Pacific Journal of Mathematics is issued monthly as of January 1966. Regular subscription rate: $\$ 190.00$ a year (5 Vols., 10 issues). Special rate: $\$ 95.00$ a year to individual members of supporting institutions.

Subscriptions, orders for numbers issued in the last three calendar years, and changes of address should be sent to Pacific Journal of Mathematics, P.O. Box 969, Carmel Valley, CA 93924, U.S.A. Old back numbers obtainable from Kraus Periodicals Co., Route 100, Millwood, NY 10546.

The Pacific Journal of Mathematics at P.O. Box 969, Carmel Valley, CA 93924 (ISSN 0030-8730) publishes 5 volumes per year. Application to mail at Second-class postage rates is pending at Carmel Valley, California, and additional mailing offices. Postmaster: Send address changes to Pacific Journal of Mathematics, P.O. Box 969, Carmel Valley, CA 93924.

PUBLISHED BY PACIFIC JOURNAL OF MATHEMATICS, A NON-PROFIT CORPORATION

Copyright $\odot 1986$ by Pacific Journal of Mathematics 


\section{Pacific Journal of Mathematics}

\section{Vol. 122, No. 2 \\ February, 1986}

Gideon Amit and David Chillag, On a question of Feit concerning character values of finite solvable groups ......................257

Constantin Gelu Apostol and Frank Larkin Gilfeather, Isomorphisms modulo the compact operators of nest algebras ................263

Parviz Azimi and James Neil Hagler, Examples of hereditarily $l^{1}$ Banach

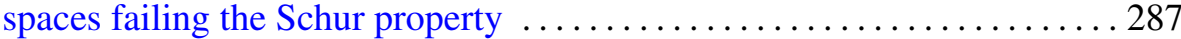

Brian Evan Blank, Boundary behavior of limits of discrete series representations of real rank one semisimple groups . . . . . . . . . . 299

Jeffrey Carroll, Some undecidability results for lattices in recursion theory

Gerald Howard Cliff and Alfred Rheinhold Weiss, Crossed product and

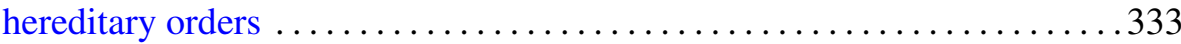

Ralph Cohen, Realizing transfer maps for ramified coverings . . . . . . . . 347

Ronald James Evans, Hermite character sums . .................. 357

C. L. Frenzen and Roderick Sue-Chuen Wong, Asymptotic expansions of the Lebesgue constants for Jacobi series . . . . . . . . . . . . . . . . 391

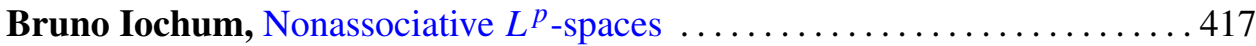

John McDonald, Unimodular approximation in function algebras ....... 435

John Robert Quine, Jr., Ramification and unintegrated value distribution . . 441

Marc Raphael, Commutants of quasisimilar subnormal operators ........ 449

Parameswaran Sankaran and Peter Zvengrowski, On stable

parallelizability of flag manifolds

Helga Schirmer, A relative Nielsen number

Barry Simon, Schrödinger semigroups on the scale of Sobolev spaces . . . . . 475

Viakalathur Shankar Sunder, Stochastic integration in Fock space

Jan de Vries, A note on the $G$-space version of Glicksberg's theorem 